\title{
Water and Wastewater Services in Non-Metropolitan New South Wales: A Critical Analysis of the Report of the Independent Inquiry
}

\author{
Brian Dollery ${ }^{1}$
}

\begin{abstract}
The Report of the Inquiry into water services in non-metropolitan New South Wales recommended that the state's local water utilities be 'aggregated' into 'regional groups organised either by means of a "binding alliance" model, a "council-owned regional water corporation" model, or the "status quo for some large general purpose councils and county councils". This paper critically examines these recommendations in the light of existing theoretical and empirical literature on structural reform in Australian local government generally, and water-utility reform specifically.
\end{abstract}

\section{Introduction}

For more than a century structural change has been the main weapon in the arsenal of Australian local government policymakers in all state and territory jurisdictions (Vince 1997). Moreover, the application of structural-change policies to Australian local government has almost always taken the form of compulsory mergers of small neighbouring local councils into larger organisational entities, invariably on the rationale that not only is 'bigger better' in terms of the range and quality of local service provision, but also that 'bigger is cheaper', thus yielding operational cost savings (Dollery, Byrnes and Crase 2008a).

While the great majority of structural-reform programs in local government have focused on the forced amalgamation of local councils (Dollery, Crase and Johnson 2006), not all policy has been directed at local authorities as discrete entities. On various occasions, the legislators for local government have sought to reconfigure specific aspects of local government service provision through structural change. For example, in 1994, the Victorian state government compulsorily removed water and wastewater provision from local government; this process involved the consolidation of around 140 non-metropolitan water providers into just 15 state-owned urban water authorities in country Victoria, with no compensation paid to local councils (Victorian Auditor-General's Office

\footnotetext{
${ }^{1}$ Centre for Local Government, University of New England, bdollery@une.edu.au. The author would like to thank an anonymous referee as well as the Editor for helpful comments on an earlier draft of the paper.
} 
2000). In 2005, further rationalisation occurred, reducing the number of non-metropolitan utilities to 13 entities.

Apparently inspired by the Victorian experience, in late 2007 the New South Wales government set in motion a policy process under the auspices of an inquiry aimed at 'reforming' water and wastewater provision in non-metropolitan NSW. In its Report of the Independent Inquiry into the Secure and Sustainable Urban Water Supply and Sewerage Services for Non-Metropolitan NSW, presented in December 2008, the Inquiry (2008: 6) proposed numerous recommendations for the reform of water and wastewater services, including the structural 'reconfiguration' of the industry through the 'aggregation' of the existing local water utilities into 'regional groups'. Further, the Inquiry argued that its proposed regional groups should adopt one of three possible institutional vehicles. This paper seeks to assess the wisdom of these two structural-reform recommendations presented by the Inquiry in the light of contemporary theoretical and empirical knowledge in the area.

\section{The New South Wales Water Inquiry Recommendations}

On 15 August 2007, the (then) NSW Minister for Water Utilities, Nathan Rees, announced an Inquiry into the Secure and Sustainable Urban Water Supply and Sewerage Services for Non-Metropolitan NSW. The ambit of the Inquiry lay in the 104 water utilities which provide urban water supply and sewerage in rural and regional NSW, with Sydney Water, Hunter Water, the Gosford City Council water supply authority and the Wyong Shire Council water supply authority deliberately excluded from the Inquiry.

In December 2008 the Inquiry's Final Report argued that the 104 local water utilities presently operating in non-metropolitan NSW should be 'aggregated' into ' 32 regional groups'. Moreover, it recommended that 'three organisational structure options should be considered' for the proposed regional groups; the 'binding alliance' model 'for planning and technical functions', the 'council-owned regional water corporation' model, and the 'status quo for some large general purpose councils and county councils'.

The Inquiry observed that both "the "binding alliance" and "status quo" options allow councils to retain ownership and management of water supply and sewerage assets and to continue providing customer services'. However, it noted that the 'council-owned regional water corporation' model involved 'the transfer of water supply and sewerage assets, related staff and service delivery responsibilities from councils to the corporation' and added the stipulation that those 'councils that are the beneficiaries of the corporation's services would be the only shareholders of the corporation'.

The two main recommendations in the Final Report followed from its analysis of the 'challenges facing the non-metropolitan urban water supply and sewerage 
industry'. From this analysis, the Final Report drew the following general conclusions: Observed performance levels measured against indicators listed in the 2006/07 NSW Water Supply and Sewerage Performance Monitoring Report, for both the water and sewerage services, showed that 'levels of performance are variable and that, in particular, small water utilities do not perform well compared to large water utilities in the implementation of the Best Practice Management of Water Supply and Sewerage Guidelines'. Moreover, 'the adoption of these guidelines is fundamental to long-term business sustainability'. The Final Report then identified 'business sophistication' and 'operating scale' as the 'two major attributes for future sustainability' for the industry.

The Final Report (2008: 29) explicitly acknowledged that 'economies of scale are not evident in water and wastewater services'. It observed further that 'in regard to operating scale there are conflicting views regarding the desirability of increasing the size of water supply and sewerage service providers'. On the one hand, "those not supportive of "regionalising" or increasing the size of individual utilities are of the view that regionalisation and larger utilities will impact detrimentally on local council viability, employment and small communities'. On the other hand, 'there are elements of local water-utility performance that are related to utilities' size' which derive from 'the fact that many smaller utilities do not have the resources or expertise to perform at a level of competence displayed by some of the larger water utilities'. While sympathetic to the latter view, the Inquiry (2008: 29) nonetheless recognised that if the presumption that utility size was indeed related to superior observed performance, then this could be addressed through either 'resource sharing among councils' or 'organisational restructuring' as 'some of the options that need to be examined'.

These conclusions led the Final Report to examine in detail the various policy options for 'aggregating' or 'regionalising' existing council operations, as well as 'business structure options' that would 'drive efficiency improvements while ensuring that the impacts on local council viability, employment and local communities are minimal'. We will consider critically its deliberations on these two questions separately below.

\section{The 'Aggregation' Recommendation}

Against the background of submissions to the Inquiry and the spatial dispersion of local water utilities in non-metropolitan NSW, the Final Report considered only two aggregation options in Chapter 4: 'Regional Aggregation' and 'Catchment Aggregation'. Since the 'Regional Aggregation' approach represented the preferred option of the Inquiry, we consider only this option in detail. ${ }^{2}$

\footnotetext{
2 The second-best 'aggregation' proposal put forward in the Final Report (2008: 36-7) consists of the 'Catchment Aggregation' option, which yields 15 aggregations or groupings of local water utilities.
} 
'Six criteria' formed the basis for 'determining the size and composition' (pp.33-4) of the 'Regional Aggregation' option:

- Each aggregation of local water utilities should exceed 'at least 10000 connected properties', with this minimum size stipulated because (a) 'non-metropolitan local water utilities above this size in NSW generally demonstrate superior performance'; and (b) it represents the 'minimum size for inclusion in reporting under the National Water Initiative's National Performance Framework'.

- Each aggregation should have an 'annual revenue of at least \$10 million' on grounds that 'properly managed local water utilities with such revenues are financially resilient, readily able to raise capital and service debt and attract skilled staff'; a criterion which 'generally' overlaps with the 10000 connected properties stipulation.

- Each aggregation should be 'sensitive to catchment boundaries' since 'environmental catchments create natural boundaries around water sources and receiving bodies'.

- Each aggregation should build on 'existing alliances between local water utilities' to the maximum extent possible, such as a 'Regional Organisation of Council grouping', of which in non-metropolitan NSW there are 12 groupings.

- Each aggregation should contain 'a major regional centre' since these centres have the 'size/scale'.

- Each aggregation should be consistent with 'submissions made to the Inquiry in order to ensure that 'as far as possible the aggregations reflect the suggestions provided in submissions and presentations to the Inquiry'.

The 'Regional Aggregation' option contains 32 groupings of local water utilities, which are set out in Appendix 1 of the Final Report and illustrated in Map 5 (p.36).

The results of this aggregation exercise were as follows: 14/15 binding alliances, two sewerage alliances, one/three 'council-owned regional water corporations, eight 'stand-alone water supply and sewerage utilities', two/three county councils, and three 'stand-alone water supply authorities'. In cases where a range of entities is recommended, the Final Report proposes alternative structures for some groupings.

In addition to these proposals, the Final Report (2008: 115) made recommendations regarding the 'special cases' of existing County Councils under its preferred structural-reform option of regional aggregation, which included the Goldenfields Water County Council, Riverina Water County Council, MidCoast Water County Council and the Rous Water and Central Tablelands Water County Councils. It also noted that if a Far Western Binding Alliance is established, comprising Broken Hill, Central Darling and Bourke and Brewarrina, 
then special care should be taken due to the vast distances involved and the high incidence of socioeconomic disadvantage. Finally, the Final Report recommended that the Fish River and Cobar Water Board continue to operate as before.

\section{'Aggregations' and Economies of Scale}

Even compared with the scant literature on amalgamation of councils, very little research has been directed at the water and sewerage functions of local councils, with the notable exceptions of the Allan Report (2006), Byrnes (2008), Byrnes, Dollery, Crase and Villano (2008a; 2008b) and Dollery (2008). Serendipitously, almost all of the very limited work that has been done in this area has focused mainly on an empirical evaluation of the efficiency of water and wastewater provision in the non-metropolitan regions of NSW and Victoria as a case study of a 'natural experiment'. As we noted earlier, while Victoria has 'regionalised' water and wastewater services through forced amalgamation, NSW has yet to embark on this course of action, which has afforded researchers an excellent opportunity to compare the relative efficiency of these two approaches.

With respect to wastewater, in addition to the seminal earlier work in the Allan Report (2006), Byrnes, Dollery, Crase and Villano (2008a) considered the efficiency characteristics of local wastewater services in non-metropolitan NSW and Victoria by examining 14 Victorian and 42 NSW water utilities over the period July 2000 to June 2004. Two major conclusions can be drawn from this analysis. Firstly, scale economies do not exist in wastewater services and other factors predominant in determining relative efficiency, especially the proportion of residential users compared with industrial users and the composition of governance boards. The main policy implication flowing from this analysis was that 'bigger is not better' and thus 'regionalization' could not hope to gain any economic benefits from scale economies in wastewater. Secondly, the Allan Report (2006) recommended cooperation between councils on the acquisition and sharing of scarce skilled employees, while Byrnes, Dollery, Crase and Villano (2008b) showed that the composition of water-utility governing boards should be changed to include more people with specialized expertise. In policy terms, it follows that wastewater-utility reform in NSW should concentrate on enhancing council cooperation in skills sharing and the composition of governing boards rather than on structural change.

With respect to water services, very similar conclusions emerge. In an interstate efficiency study, Byrnes, Dollery, Crase and Villano (2008b) examined 52 water utilities from regional NSW and Victoria in order to measure the relative productive efficiency of these water utilities over the four year period 2000 to 2004. The policy implications of this work are as follows: there are no significant scale economies in water services and other factors determine relative efficiency, such as groundwater availability, conservation measures, the proportion of 
industrial users, and especially the composition of governance boards. It follows that in local water services 'bigger is not better' and thus 'regionalization' could not hope to reap any economic benefits from scale economies. In addition, as in the case of wastewater services, the Allan Report (2006) recommended that adjacent councils share skilled employees and Byrnes, Dollery, Crase and Villano (2008b) argued that the composition of water-utility governing boards should reflect more people with specialised expertise. In common with wastewater, it would thus seem that water-utility reform in NSW should concentrate on enhancing council cooperation in skills sharing and modifying the composition of governing boards.

In a pre-emptive defence of the Regional Aggregations proposed under preferred option 1, the authors of the Final Report made special reference to a lengthy submission to the Inquiry by Dollery (2008), in the form of an independent report produced for the United Services Union, which considered the problem of the empirical magnitude of scale economies in water and wastewater services. Dollery (2008) drew heavily on the Allan Report (2006), Byrnes (2008), and Byrnes, Dollery, Crase and Villano (2008a; 2008b) in order to argue that not only did no scale economies exist in water and wastewater services, but that existing work, which compared the Victoria and NSW industries, showed that diseconomies of scale were apparent in Victoria in the aftermath of that state's radical restructuring program.

In an effort to rebut this line of criticism, the authors of the Final Report (2008: 35) observed that 'the United Services Union's [Dollery 2008] submission suggests that diseconomies of scale may be generated by "regionalisation" on grounds that "research into the relative efficiency of NSW and Victorian water utilities referred to in Chapter 3 [of the Final Report] indicates that while the Victorian water utilities tend to be more technically efficient, the efficiency gap is reduced by the diseconomies of scale affecting the Victorian water utilities'. The Inquiry thus accepted that 'there are additional costs to being "too big"' in water and wastewater services. In other words, the Final Report fully endorsed the arguments on scale diseconomies advanced in Dollery (2008), which present serious problems for any proposals recommending structural change aimed at increasing the size of water utilities, such as the Regional Aggregation option supported in the Final Report.

The thrust of this empirical argument is parried in the Final Report (2008: 35) using the following line of argument: 'The 13 Victorian non-metropolitan water utilities serve an average 46000 connected properties (range 14000 to 127000 properties)' whereas, by contrast, 'the size of groups proposed in Option 1 would vary between approximately $8300-60000$ connected properties'. In essence, the authors of the Final Report contend that scale diseconomies will not afflict the proposed Regional Aggregation option groupings of water and 
wastewater services because they are, on average, smaller than their Victorian counterparts, when size is measured in terms of connected properties, rather than some other factor, such as gross spatial area serviced.

This argument is problematical. Quite apart from the obvious point that the size of the proposed groupings for non-metropolitan NSW overlap considerably with the amalgamated Victorian utilities, with some recommended NSW groupings exceeding the size of their Victorian equivalents in terms of connected properties, it also ignores important qualifications provided by Byrnes (2008), Byrnes, Dollery, Crase and Villano (2008a; 2008b) and Dollery (2008) as well as well-known arguments in the literature on the efficiency measurement of local service provision (see, for instance, Worthington and Dollery 2000a).

In the first place, for both sewerage and wastewater services, Byrnes (2008), Byrnes, Dollery, Crase and Villano (2008a; 2008b) and Dollery (2008) were at pains to stress that factors other than the scale of operations and the composition of governance boards were at play in determining efficiency. For example, in the case of wastewater, the treatment of sewage depends (in part) on where effluent is discharged, a factor often beyond the control of local councils. Similarly, Byrnes, Dollery, Crase and Villano (2008a) argued that the proportion of residential users compared with industrial users, which councils typically cannot influence substantially, had a significant impact. In an analogous vein, for water services, Byrnes, Dollery, Crase and Villano (2008b) found that external factors, including access to groundwater, drought-induced conservation measures, and the proportion of industrial users, affected efficiency.

These observations on the comparative efficiency of water and wastewater utilities echo a much broader theme in the international empirical literature on performance monitoring (Worthington and Dollery 2008) and efficiency measurement in local government service provision (Worthington and Dollery 2000a; 2000b), which has an Australian local government strand (Worthington and Dollery 2001; 2002). It is well-known that numerous 'non-discretionary' factors, which cannot be controlled by local authorities, can have a decisive impact on the economic efficiency of service provision. Given the vast differences in climatic, environmental, topographical and other natural factors, as well as water endowments, between the different local government areas in non-metropolitan NSW, it is hardly surprising that differences in council performance in service delivery have emerged. However, because a substantial, and largely unknowable, proportion of differences in performance are directly attributable to non-discretionary external factors, public policy must take this into account. Structural change enacted on the assumption that councils have complete discretion over operational efficiency is thus unwise.

A further problem with the Regional Aggregation groupings proposed in the Final Report revolves around the case for a uniform minimum size for these 
groupings of 10000 connected properties. In their analysis in Chapter 3 of the Final Report, its authors argued that existing small water utilities did not perform well compared to their larger counterparts on the implementation of the Best Practice Management of Water Supply and Sewerage Guidelines, as measured in terms various specific compliance indicators. While this is certainly true at first sight, a well-known and significant problem with reporting frameworks, such as the NSW Best Practice Management of Water Supply and Sewerage Guidelines, is that they rely on partial performance indicators, expressed in absolute terms. Comparing the 'performance' of different utilities is thus of severely limited value, since a given utility may be the benchmark for one indicator, in the medium range for a second indicator, and 'bottom of the class' for a third (Worthington and Dollery 2008). Ranking thus becomes meaningless.

A final noteworthy feature of the 32 groupings proposed under the Regional Aggregation option is that not all groupings meet the six criteria for structural aggregation set out in the Final Report. In this regard, the authors of the Final Report (2008: 35-6) observe that 'a majority of the 32 proposed groups satisfy the aggregation criteria; however, not all do'. By way of illustration, the Final Report provided four examples of cases which did not fully met the criteria:

- The proposed Western Ranges water utility (Yass Valley, Gundagai, Tumut and Tumbarumba) and the Snowy Monaro Region (Cooma-Monaro, Snowy River and Bombala) both had 'slightly less than 10000 connected properties';

- The proposed Snowy Monaro Region will have 'an annual combined revenue of about $\$ 9$ million';

- Only 17 of the 32 proposed groupings had a 'major regional centre'; and

- Only 23 of the 32 proposed groupings 'have been based on, or are exactly defined by, LWU submissions to the Inquiry'.

These considerations suggest that the 32 Regional Aggregate groupings should be regarded as indicative rather than mandatory. Put differently, the problems we have identified indicate that sewerage and water-utility restructuring should depend on the particular circumstances of specific councils rather than a blanket prescription for all councils.

\section{The Recommendations on Organisational Structure}

The second major recommendation on structural change in the Final Report dealt with the optimal organisational arrangements for the entities identified under the preferred Regional Aggregation groupings.

The Report concluded that the Binding Alliance model, Council-owned Regional Water Corporations, and the Status Quo model ('for some large local water utilities'), all had 'the potential to meet all of the evaluation criteria' (p.61). In the light of the submissions it received, the Final Report (2008: 61) also emphasised that 'many councils favour models that can be adopted to minimise 
impacts on asset ownership, revenues, employment and communities - models which negate the need for wide-ranging structural change', which 'in most cases' would suggest the formation of 'a regional binding alliance to deliver water supply and sewerage services'. It even recognised potential problems with the Binding Alliance model: 'The binding alliance model is not perfect because there is potentially tension between strategic decision making and program implementation as these functions are conducted by separate legal entities', which could be remedied by 'close cooperation between the alliance entity and the member councils, together with concise service agreements backed by legislative force'.

This analysis is in broad agreement with the Davis, Paddon and Chong (2008: 17) assessment of their conceptually identical Regional Mandatory Alliance, which they contend represents 'a minimalist' option since it 'imposes the least change' on local water utilities. Under this model, water utilities 'retain ownership of assets; conduct local operations; and make local decisions'. Moreover, 'an agreed scope of pooled activities would be set up centrally and participants simply pay pro rata for their share of the services'. The authors contend that membership of the model 'must be mandatory' otherwise 'it risks falling apart in the face of difficulties or a lack of interest'.

In comparison with the Council-Owned Regional Water Corporation model, the only other structural-change organisational model recommended in the Final Report, bearing in mind the third option is the Status Quo model, both Davis, Paddon and Chong (2008) and the authors of the Final Report (2008) seem to be correct that the Binding Alliance model represents a 'minimalist' option. However, the analysis of the Binding Alliance model in the Final report, as well as the Council-Owned Regional Water Corporation model, leaves many questions unanswered.

By far the most important of these neglected aspects of the Binding Alliance model, which is recommended for $14 / 15$ of the 32 proposed Regional Aggregations, and by far the most 'restructured' of these groupings, as we can see from Appendix 1, Map 5, resides in the thorny problem of costing this model. Indeed, the authors of the Final Report (2008: 61) freely admit to ignoring this critical question by noting that 'comprehensive costing has not been conducted for the models discussed in this chapter'. Instead the Final Report has relied exclusively on a single submission for information on costing the Binding Alliance. It noted that 'RAMROC has provided indicative costs for its binding alliance model'. On the basis of these costs, the Final Report estimated that 'each new alliance would require between $\$ 375000$ and $\$ 720000$ to resource per annum', which equates to between roughly $\$ 7$ million to $\$ 14$ million across NSW per year. This impost is defended on grounds that 'the benefits from this model, including professional strategic planning and access to specialist technical skills, 
which are essential in any future delivery arrangements are expected to more than counterbalance these costs' (p.62).

The highly unsatisfactory nature of this ad hoc method of costing is underlined by an analysis of the original submission by RAMROC (2008), which outlines the 'methodology' used by RAMROC in its costing procedure. RAMROC (2008: 5) arrived at its costings as follows: 'As a straw man for the sake of this submission, the initial format for RAMROC Water could be an office with a general manager, an engineer and an administrative officer' (original emphasis). From this, RAMROC divined that 'the cost of that service would be roughly, divided amongst 18 councils (smallest six paying \$20k pa; medium ten paying $\$ 40 \mathrm{k}$ pa and the largest two paying $\$ 75 \mathrm{k} \mathrm{pa)'.} \mathrm{In} \mathrm{addition,} \mathrm{in} \mathrm{its} \mathrm{submission,}$ RAMROC observed that 'finding answers to the big questions will take both time and money' (pp. 5-6). Thus,

completing a rigorous analysis of options, consulting with member councils (not all are fully committed at the time of writing) and developing a sound, flexible business plan for RAMROC Water will take at least six months, and the costs would be approximately $\$ 200 \mathrm{k}$ for an external consultant, plus all the member councils' investments of time and resources to support the work.

RAMROC suggested these latter funds should be provided by the NSW government. $^{3}$

The highly arbitrary 'back-of-the-envelope' nature of this costing method cannot be over-estimated. Indeed, it is easy to illustrate that the Final Report has erred badly in using the RAMROC (2008) submission calculations as the basis for its cost estimates. In the first place, the $\$ 375000$ and $\$ 720000$ range advanced in the Final Report (2008: 62) completely ignores establishment costs. ${ }^{4}$ Secondly, with 18 member councils, RAMROC would be by far the largest Binding Alliance in NSW, with the next largest (Central Tablelands Region) containing nine councils, and most proposed models of this kind incorporating only between five and two councils. It follows that per-capita costs for both member councils and connected properties would vary enormously. Thirdly, with the estimated $\$ 375000$ and $\$ 720000$ range, how can this provide a Binding Alliance office, a general manager, an engineer and an administrative officer in all cases? Finally, no estimates of the influence of purported economies of scope are made.

\footnotetext{
3 These establishment costs are completely ignored in the Final Report, despite the heavy potential per-capita impost they could impose on small councils.

4 Appendix 3 in the Final Report (2008: 121) erroneously refers to the $\$ 375000$ and $\$ 720000$ range proposed (as 'a straw man') by RAMROC (2008: 5) as 'initial set up costs'. In fact, RAMROC postulated these costs as annual ongoing costs and are used in this manner in the calculations performed in the Final Report in Appendix 3.
} 
The ad hoc nature of the costing provided for the Binding Alliance in the Final Report serves to undermine many of the favourable claims made in support of this model. Perhaps the most worrying dimension of the inadequate costing is the potential for the costs of small Binding Alliances to be far higher than their larger counterparts, since almost all the costs of the Binding Alliance organisational entity are fixed costs, predominantly in the form of salaries. Thus for Binding Alliances consisting of a few members, these fixed costs will be spread across only a limited number of councils thereby raising the impost on individual municipalities. This suggests that a cautious 'case-by-case' approach should be taken to Regional Aggregation. If individual councils can demonstrate excessive costs or unusual circumstances, then provision should be made for them to be exempt from Regional Aggregation.

\section{Concluding Remarks}

What general policy implications emerge from our analysis of the two main structural change proposals developed in the Final Report? In the first place, we have seen that serious reservations exist on the specification of the Regional Aggregation groupings.

For example, we have demonstrated that the Final Report has failed to recognise the significance of 'non-discretionary' factors, beyond the control of local authorities, which have a profound influence on the economic efficiency of water and wastewater service provision. Given the drastic physical and human differences confronted by councils in different parts of NSW, this failure can have ominous consequences for some of the proposed Regional Aggregations. Similarly, we showed that the Final Report had misguidedly used only partial performance indicators drawn from the NSW Best Practice Management of Water Supply and Sewerage Guidelines to gauge performance, despite the well-known problems associated with this approach. This had led to the use of false assumptions on council size and council efficiency in the Final Report. Moreover, the rough and ready nature of many of the Regional Aggregation groupings is further underlined by the fact that many of these groupings did not even meet the six criteria for structural aggregation developed in the Final Report. These deficiencies in the Regional Aggregation groupings strongly suggest that groupings should be used only on an indicative basis and membership should accordingly be on a voluntary basis.

Secondly, the Final Report proposed three organisational models suitable for employment in the Regional Aggregation context: The Council-Owned Regional Water Corporation model, the Binding Alliance model, and the Status Quo model (in some limited instances). With respect to the application of these models, the Binding Alliance is by far the most important model since it is the recommended option for a great majority of council groupings. However, we have demonstrated that the Final Report unwisely relied on the 'straw man' estimates provided by 
RAMROC (2008) in its submission to the Inquiry. This was unfortunate in several respects, not least the fact that the RAMROC figures were designed for the largest grouping and not for the 'median' grouping. Moreover, the Final Report completely ignored establishment costs and their potential impact on small groupings. Finally, the Final Report made no attempt to estimate scope economies in its efforts at costing. The policy consequences of these shortcomings strongly suggest that the financial characteristics of the Binding Alliance are not understood and thus the adoption of this organisational model should be contingent on individual council circumstances rather than on compulsion.

\section{References}

Allan, P. 2006, Are Councils Sustainable? Final Report: Findings and Recommendations, Independent Inquiry into Local Government Inquiry (LGI); Sydney: NSW Local Government and Shires Association.

Byrnes, J. 2008, 'Putting Water to Work: A Study of Relative Economic Efficiency in the Urban Water and Wastewater Sectors of Regional New South Wales and Victoria', unpublished PhD thesis, University of New England, Armidale.

Byrnes, J. Crase, L., Dollery, B. E. and Villano, R. 2008a, 'The Role of Governance Structures in Urban Infrastructure Management and Service Delivery: The Case of Wastewater Utilities in Regional Australia', unpublished paper, University of New England, Armidale.

Byrnes, J., Crase, L. Dollery, B. E., and Villano, R. 2008b, 'Putting Water to Work: Urban Water Utilities in Regional New South Wales and Victoria', Working Paper 19-2007, Centre for Local Government, University of New England, Armidale.

Davis, C., Paddon, M. and Chong, J. 2008, Options Paper on the Inquiry into Secure and Sustainable Urban Water Supply and Sewerage Services for Non-Metropolitan NSW, Institute for Sustainable Futures, University of Technology in Sydney, Sydney.

Dollery, B. E. 2008, Independent Report prepared for the United Services Union on possible changes to water and wastewater services from the Inquiry into the Secure and Sustainable Urban Water Supply and Sewerage Services for Non-Metropolitan NSW, United Services Union, Sydney.

Dollery, B. E., Byrnes, J. D. and Crase, L. 2008a, 'A Note on Structural Reform in Australian Local Government', Australian Journal of Political Science 43(2): 333-39.

Dollery, B. E., Byrnes, J. D. and Crase, L. 2008b, 'Australian Local Government Amalgamation: A Conceptual Analysis of Population Size and Scale 
Economies in Municipal Service Provision', Australasian Journal of Regional Studies 14(2): 167-75.

Dollery, B. E., Crase, L. and Johnson, A. 2006, Australian Local Government Economics, UNSW Press, Sydney.

NSW Department of Water and Energy 2008, Report of the Independent Inquiry into Secure and Sustainable Urban Water Supply and Sewerage Services for Non-Metropolitan NSW (Final Report), available at $>$ http://www.dwe.nsw.gov.au/water/utilities_local.shtml $<$. Consulted 25 February 2009.

RAMROC Water 2008, Inquiry into Secure and Sustainable Urban Water Supplies and Sewerage Services for Non-Metropolitan NSW: RAMROC Water, Murray Regional Organisation of Councils.

Vince, A. 1997, 'Amalgamations', in B. E. Dollery and N. A. Marshall (eds), Australian Local Government: Reform and Renewal, Macmillan, Melbourne: 151-71.

Worthington, A. C. and Dollery, B. E. (2008), 'Performance Measurement in Australian Local Government', ICFAI Journal of Public Administration, $4(2), 7-27$.

Worthington, A. C. and Dollery, B. E. 2002, 'Incorporating Contextual Information in Public Sector Efficiency Analyses: A Comparative Study of NSW Local Government', Applied Economics 34(1): 453-64.

Worthington, A. C. and Dollery, B. E. 2001, 'Measuring Efficiency in Local Government: An Analysis of New South Wales Municipalities' Domestic Waste Management Function', Policy Studies Journal 29(2): 232-49.

Worthington, A. C. and Dollery, B. E. 2000a, 'Measuring Efficiency in Local Government', Public Productivity and Management Review 23(4): 469-85.

Worthington, A. C. and Dollery, B. E. 2000b, 'An Empirical Survey of Frontier Efficiency Measurement Techniques in Local Government', Local Government Studies 26(2): 23-52. 